\title{
Lung autotransplantation technique for postpneumonectomy- like syndrome
}

Fengshi Chen, MD, ${ }^{a}$ Akihiro Takahagi, MD, ${ }^{a}$ Kazuhisa Sakamoto, MD, ${ }^{b}$ and Hiroshi Date, MD, ${ }^{a}$ Kyoto, Japan

From the Departments of ${ }^{\mathrm{a}}$ Thoracic Surgery and ${ }^{\mathrm{b}}$ Cardiovascular Surgery, Kyoto University Graduate School of Medicine, Kyoto, Japan.

Disclosures: Authors have nothing to disclose with regard to commercial support.

Received for publication April 25, 2015; revisions received June 7, 2015; accepted for publication June 14, 2015; available ahead of print July 26, 2015.

Address for reprints: Hiroshi Date, MD, Department of Thoracic Surgery, Kyoto University Graduate School of

Medicine, 54 Shogoin Kawahara-cho, Sakyo-ku, Kyoto 606-8507, Japan (E-mail: hdate@kuhp.kyoto-u.ac.jp). J Thorac Cardiovasc Surg 2015;150:e45-7

$0022-5223 / \$ 36.00$

Copyright $(2015$ by The American Association for Thoracic Surgery

http://dx.doi.org/10.1016/j.jtcvs.2015.06.048

Postpneumonectomy syndrome is a rare but occasionally life-threatening complication of pneumonectomy. ${ }^{1}$ This syndrome is also known to occur in the absence of pneumonectomy, in which case it is termed postpneumonectomylike syndrome. ${ }^{2}$ Currently, surgical correction is the primary treatment option for postpneumonectomy syndrome, but only a few cases of the surgical treatment of postpneumonectomy-like syndrome have been reported. ${ }^{3}$ Lung autotransplantation was a technique developed for the preservation of pulmonary function in patients with centrally located lung cancer. There is also potential to use the atelectatic remaining lung in patients with postpneumonectomy-like syndrome. Herein, we discuss a patient with postpneumonectomy-like syndrome who was successfully treated with lung auto-transplantation.

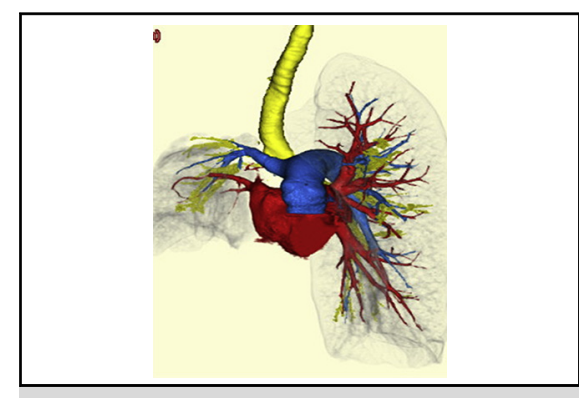

Mediastinal repositioning was successfully performed by lung autotransplantation.

\section{Central Message}

Postpneumonectomy-like syndrome was successfully treated by mediastinal repositioning with lung autotransplantation.

See Editorial Commentary page e47.

\section{CLINICAL SUMMARY}

A 70-year-old woman was referred to our hospital with severe dyspnea and hemodynamic instability during exercise. She had received a right upper lobectomy for stage I lung cancer 15 years previously. Six years later, she underwent wedge

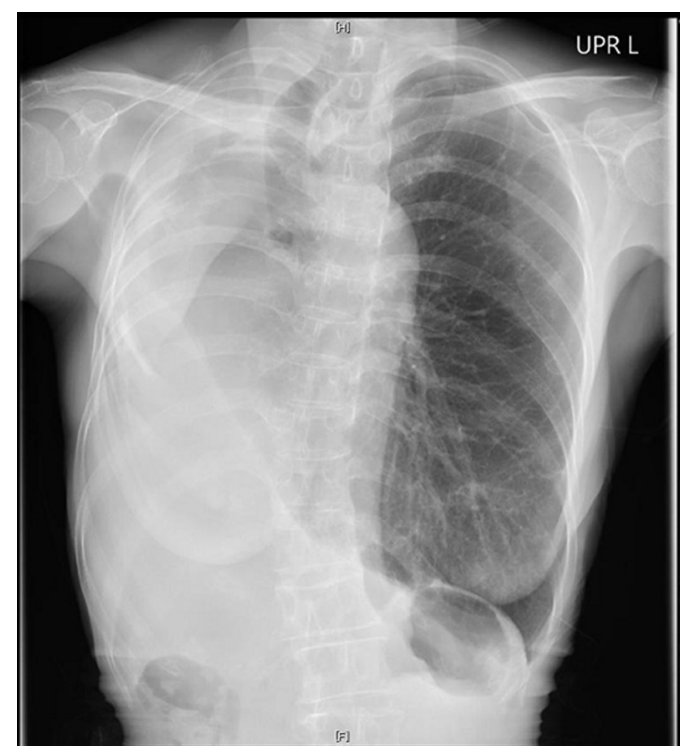

A

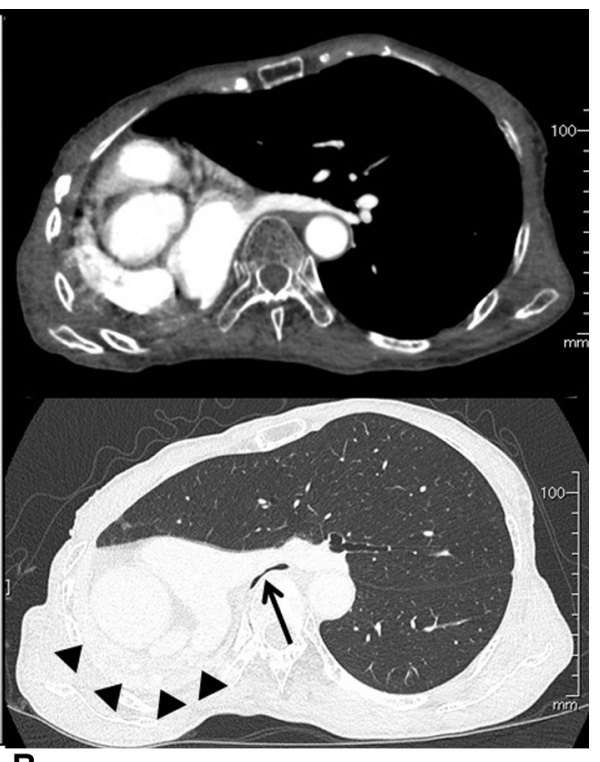

B

FIGURE 1. A, Preoperative chest roentgenography showing overinflation of the left lung. B, Chest computed tomography revealing the complete atelectasis of the remaining right middle and lower lobes (arrowheads) with a significant shift of the mediastinum. The proximal left main bronchus is extrinsically compressed (arrow). UPR L, Upright and left. 


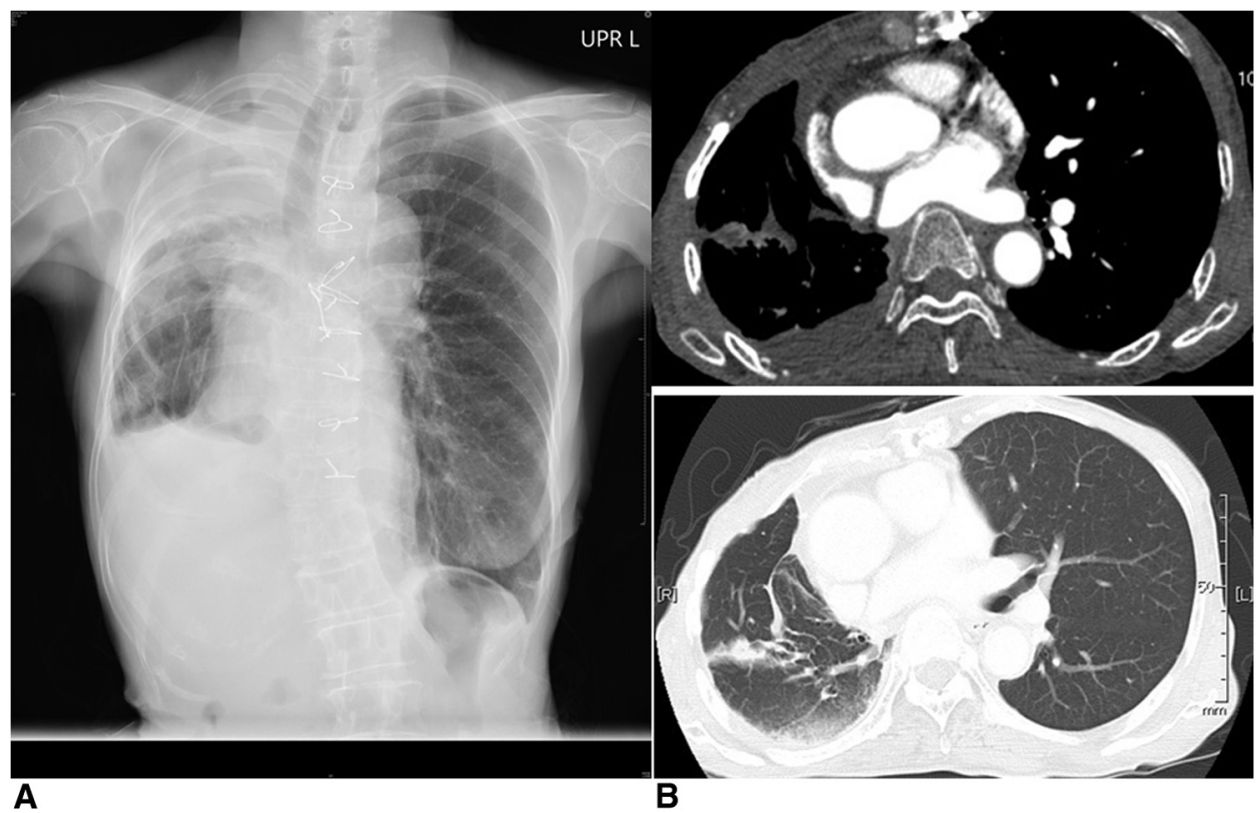

FIGURE 2. A, Postoperative chest roentgenography reveals correction of the mediastinal shift. B, Chest computed tomography at the discharge showing that the left lung was not overinflated due to the mediastinal repositioning and that the right lung was well inflated after lung autotransplantation. $U P R L$, Upright and left; $R$, right; $L$, left.

resection of the right lower lobe for a second primary lung cancer. Five years after that, she received radiation therapy for isolated right hilar lymph node metastasis. Subsequently, the patient remained in good health and without tumor recurrence for 3 years. However, 1 year ago, she experienced dyspnea on effort. Her dyspnea with hemodynamic instability exacerbated over time and she became almost completely bedridden because of her symptoms. At this point, she was referred to our hospital. Radiologic examination revealed complete atelectasis of the remaining right middle and lower lobes with a significant shift of the mediastinum (Figure 1). Bronchoscopic examination revealed an occlusion of the truncus intermedius. Positron emission tomography showed no significant uptake. The patient was diagnosed with postpneumonectomy-like syndrome. Our strategy was to surgically reposition the mediastinal shift and spare the atelectatic lung if possible.

To counter the potential for hemodynamic instability during anesthetic induction, the patient was placed on venoarterial extracorporeal membrane oxygenation through the right femoral artery and vein before general anesthesia. Dissection of the adhesions was carefully performed. The right middle lobe was resected because it appeared to be damaged to such an extent that it would not be able to function appropriately. The pulmonary artery and vein were clamped and completion pneumonectomy was performed. On another table in the operating room, a thorough examination of the explanted lung revealed that the right lower lobe was suitable for transplantation. After confirming that the atelectatic right lower lobe could be sufficiently inflated manually, sequential antegrade and retrograde pulmonary arterial flushes were performed using ET-Kyoto solution (ET-K, Otsuka
Pharmaceutical Factory Inc, Naruto, Japan). ${ }^{4}$ An intraoperative pathologic evaluation revealed no malignancy in the obstructed truncus intermedius; therefore, right lower lobe lung autotransplantation was performed. First, the right lower lobe bronchus was anastomosed to the right main bronchus. Thereafter, anastomosis of the pulmonary artery was performed. The arterial anastomosis site was accessed through the window between the superior vena cava and the ascending aorta. Finally, the pulmonary vein was anastomosed to the remaining upper pulmonary venous stump. Although postoperative respiratory support was required with noninvasive positive pressure ventilation, the patient was discharged without any limitations to her daily life 1 month after the surgery. The mediastinal shift was corrected without overinflation of the left lung and the autotransplanted right lung functioned appropriately (Figure 2). Because there was neither evidence of malignancy nor apparent postradiation changes pathologically, the final pathologic diagnosis was difficult to determine; however, the most probable diagnosis of the bronchial stricture was the postoperative mechanical change of the truncus intermedius. At present, 6 months postoperatively, the patient is alive and well without any symptoms.

\section{DISCUSSION}

The treatment of postpneumonectomy-like syndrome is generally considered on an individual basis according to the treatment of postpneumonectomy syndrome. Currently, the most widely recommended surgical treatment for postpneumonectomy syndrome involves repositioning the mediastinum and implantation of fixed-volume or expandable prostheses. ${ }^{1}$ However, in 19 patients treated with the insertion 
of 1 to 3 expandable prostheses, 8 reoperations were required due to luxation, malpositioning, herniation, or leakage of the expanders. ${ }^{5}$ In our patient, it was apparent that simple bronchial sleeve resection could not be chosen as a treatment option for several reasons, such as the long bronchial resection and evaluation of the atelectatic lobes; however, we considered the possibility that the remaining right lung could be used for mediastinal repositioning, which would eliminate the risk for the potential complications listed above.

\section{CONCLUSIONS}

We have presented the first patient with postpneumonectomy-like syndrome who was successfully treated with lung lobar autotransplantation. This novel surgical technique has the advantages of preserving pulmonary function without requiring implantation of a prosthesis into the chest.
The authors thank Drs Kenji Minakata and Kazuhiro Yamazaki for providing intraoperative cardiovascular management of the patient and Drs Keiji Tanimoto and Hajime Segawa for providing management of the patient in the intensive care unit.

\section{References}

1. Shen KR, Wain JC, Wright CD, Grillo HC, Mathisen DJ. Postpneumonectomy syndrome: surgical management and long-term results. J Thorac Cardiovasc Surg. 2008;135:1210-6

2. Veronesi G, Spaggiari L, Solli PG, Leo F, Villa G, Pastorino U. Postpneumonectomy-like syndrome after chemoradiation therapy for lymphoma. Ann Oncol. 2002; 13:1945-7.

3. Lee Y, Kim HK, Lee S, Kim H, Kim J. Surgical correction of postpneumonectomy-like syndrome in a patient with a tuberculosis-destroyed lung. J Thorac Cardiovasc Surg. 2008;136:780-1.

4. Chen F, Nakamura T, Wada H. Development of new organ preservation solutions in Kyoto University. Yonsei Med J. 2004;45:1107-14.

5. Macare van Maurik AF, Stubenitsky BM, van Swieten HA, Duurkens VA Laban E, Kon M. Use of tissue expanders in adult postpneumonectomy syndrome. J Thorac Cardiovasc Surg. 2007;134:608-12.

\title{
EDITORIAL COMMENTARY
}

\section{Autotransplantation: A novel solution for postpneumonectomy-like syndrome}

\author{
Jian-yong Ding, MD, $\mathrm{PhD}$
}

From the Department of Thoracic Surgery, Fudan University Affiliated Zhongshan Hospital, Shanghai, China. Disclosures: Author has nothing to disclose with regard to commercial support.

Received for publication June 29, 2015; revisions received July 6, 2015; accepted for publication July 6, 2015; available ahead of print Aug 5, 2015.

Address for reprints: Jian-yong Ding, MD, PhD, Department of Thoracic Surgery, Fudan University Affiliated Zhongshan Hospital, Shanghai 200032, China (E-mail: ding.jianyong@zs-hospital.sh.cn).

J Thorac Cardiovasc Surg 2015;150:e47-8

$0022-5223 / \$ 36.00$

Copyright (C) 2015 by The American Association for Thoracic Surgery

http://dx.doi.org/10.1016/j.jtcvs.2015.07.005

Postpneumonectomy-like syndrome (PPLS) is a rare but life-threatening condition. Its pathogenic mechanism and treatment are similar to those for postpneumonectomy syndrome (PPS) but without the actual resection of one side of the entire lung. Here both PPLS and PPS will be discussed together. For some unclear reason, in these patients, the heart and mediastinum excessively shift toward one side and also rotate significantly. The remaining distal trachea and main bronchus can become compressed against the vertebral column or aorta by the pulmonary artery. Excessive mediastinal shift results in progressive dyspnea and stridor, which is followed by respiratory failure or tracheomalacia if ignored. Under more unusual conditions, PPS may also result in dysphagia as a result of esophageal compression.

Without treatment, PPS can be lethal. A variety of methods to correct PPS or PPLS have been reported, but

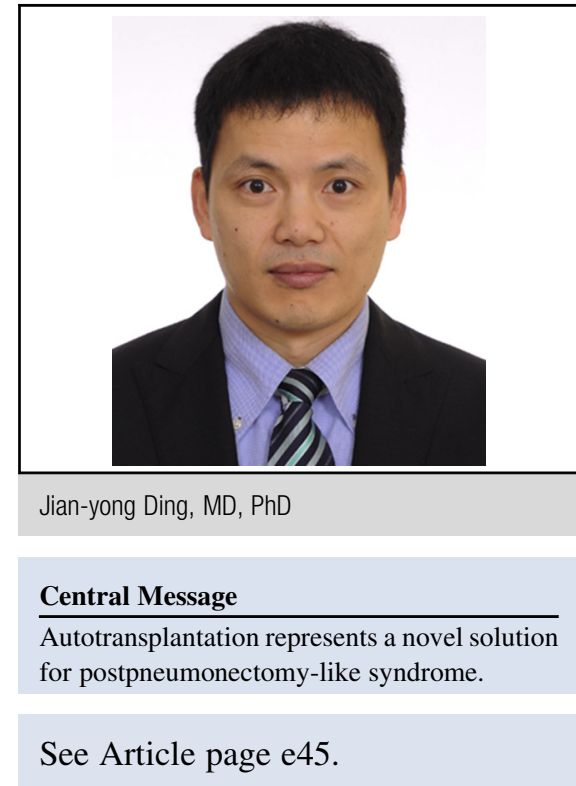

most consist of single case reports with small numbers of patients. Early attempts include bronchial stent, suture fixation of pericardium to the back of the sternum, surgical and chemical phrenectomy, and placement of prostheses 